DOI 10.37882/2223-2974.2020.11.31

\title{
НАЛОГОВО-ПРАВОВЫЕ ПОСЛЕДСТВИЯ ВЗАИМОЗАВИСИМОСТИ ЛИЦ ПО ЗАКОНОДАТЕЛЬСТВУ РОССИЙСКОЙ ФЕДЕРАЦИИ
}

\section{TAX AND LEGAL CONSEQUENCES OF THE INTERDEPENDENCE OF INDIVIDUALS UNDER THE LEGISLATION \\ OF THE RUSSIAN FEDERATION}

\section{Terekhova \\ A.Dujov}

Summary: Signs of interdependence of persons are indicated in article 105.1 of the tax code of the Russian Federation. The activities of related parties fall under tax control due to the existence of transaction control criteria in accordance with Chapter 14.1 of the tax code of the Russian Federation. Controlled transactions - transactions of related parties or equivalent transactions whose prices are controlled in accordance with article 105.14 of the tax code of the Russian Federation, this includes transactions with a turnover of more than 1 billion rubles. The author considers the criteria for recognizing transactions as controlled, and analyzes the tax and legal consequences of the interdependence of individuals under the legislation of the Russian Federation.

Keywords: interdependent entities, Tax code of the Russian Federation, controlled transactions, uncontrolled transactions, comparable transactions, market prices.
Терехова Валентина Владимировна

К.ю.н., доцент, Российский государственный гуманитарный университет wsamoiova@mail.ru

Дюжов Алексей Владимирович

К.э.н., доцент, Российский экономический университет имени Г.В. Плеханова adujov@rambler.ru

Аннотация: Признаки взаимозависимости лиц обозначены В ст. 105.1 НК РФ. В зону налогового контроля попадает деятельность взаимозависимых лиц в связи с наличием критериев контролируемости сделки согласно гл. 14.1 НК РФ. Контролируемые сделки - сделки взаимозависимых лиц или приравненные к ним сделки, цены которых контролируются согласно ст. 105.14 НК РФ, сюда попадают сделки с оборотом выше 1 млрд. рублей. В статье автором рассмотрены критерии признания сделок контролируемыми, а также проанализированы налогово-правовые последствия взаимозависимости лиц по законодательству Российской Федерации.

Ключевые слова: взаимозависимые лица, Налоговый кодекс РФ, контролируемые сделки, неконтролируемые сделки, сопоставимые сделки, рыночные цены.

бизнес, тем самым могут быть признаны взаимозависимыми. Так как список критериев, попадающих под иные основания, остается открытым, суд может «поверить» разнообразным обстоятельствам и доказательствам, выявленным налоговым органом.

В зону налогового контроля попадает деятельность взаимозависимых лиц в связи с наличием критериев контролируемости сделки согласно гл. 14.1 НК РФ. Контролируемые сделки - сделки взаимозависимых лиц или приравненные к ним сделки, цены которых контролируются согласно ст. 105.14 НК РФ [2]. При обороте по сделке между взаимозависимыми компаниями до 1 млрд. рублей сделка будет неконтролируемой.

При признании сделки контролируемой могут иметь место правовые последствия. Чаще всего отклонения в ценах сделки между взаимозависимыми лицами используется для получения более крупного вычета (при завышении налоговой базы) или уменьшения суммы налога (при занижении налоговой базы). Попадая под контроль Налоговой службы, будет проверяться корректность начисления налогов на прибыль, НДПИ, НДС и НДФЛ (для ИП). 
Проверить контролируемые сделки на соответствие рыночным ценам можно следующими способами:

1. Метод цены последующей реализации

Используется в основном в сделках по перепродаже товаров третьему лицу без переработки. В этом случае проверяется валовая рентабельность с рыночным интервалом валовой рентабельности у перепродавца.

2. Метод сопоставимой рентабельности

Применяется чаще всего, когда невозможно применить метод цены последующей реализации, затратный метод и метод сопоставимых рыночных цен. Данный метод сравнивает рыночный интервал операционной рентабельности с операционной рентабельностью стороны рассматриваемой сделки, сюда можно отнести рентабельность затрат, рентабельность активов, рентабельность продаж, рентабельность управленческих и коммерческих расходов и т.д.

3. Метод сопоставимых рыночных цен

Этот метод является основным, применяется для определения цены при реализации услуг, работ, товаров. Суть его состоит в том, что рассчитывается интервал рыночных цен по сопоставимым сделкам между применённых в сделках со взаимозависимыми лицами и в сделках между не взаимозависимыми лицами.

4. Метод распределения прибыли

Применяется, когда нематериальные активы сторон анализируемой сделки оказывают большое влияние на уровень рентабельности, а также когда не представляется возможным применить выше-обозначенные методы. Суть метода заключается в сопоставлении распределении прибыли между сторонами сопоставимых сделок и реального распределения совокупной прибыли между участниками взаимозависимой сделки.

5. Затратный метод

Метод заключается в сопоставлении рыночного интервала валовой рентабельности затрат и валовой рентабельности затрат, полученной продавцом.

Все внутрироссийские сделки, совершаемые между взаимозависимыми лицами, будут являться контролируемыми, если оборот по ним выше 1 млрд. рублей, малый и средний бизнес в эту категорию не попадает. Критерии признания сделок не контролируемыми описаны в п. 4 ст. 105.14 НК РФ [3].

Представляет интерес письмо ФНС от 02.11.2012 № ЕД-4-3/18615 [4]. В нем налоговая служба предупреждает о том, что будет в соответствии с нормами гл. 14.3 НК РФ проводить камеральные проверки, используя метод выявления необоснованной налоговой выгоды и контролировать любые, дающие повод говорить о нерыночных ценах с целью уклонения от налогов, сделки взаимозависимых лиц. По факту это может вылиться в доначислении налогов согласно гл. 14.2 НК РФ (п. 5 ст. 105.3 НК РФ), тем не менее, имеются несколько судебных решений, согласно которым ФНС не имеет полномочий проведения проверки цен по неконтролируемым сделкам.

Для дальнейшего налогообложения лица должны быть признаны взаимозависимыми, это становится возможным: если лица самостоятельно признали свою взаимозависимость, по решению суда и в силу положений закона. Физические лица также могут быть признаны взаимозависимыми, как уже было отмечено выше согласно п. 2 ст. 105.1 близкие родственники признаются таковыми. В этом случае, они лишаются права получения налогового вычета на основе сделок (п. 5 ст. 220 НК РФ) [5], заключенных между собой, даже при наличии реальных денежных расчетов и уплаты НДФЛ.

Кроме налогового контроля над сделками, взаимозависимость несет ограничение в правах. Как пример, мы уже приводили выше лишение права на имущественный вычет у физических лиц, у юридических лиц не действует право на льготу, к примеру, согласно п. 25 ст. 381 НК РФ при приобретении имущества у взаимозависимой компании не может быть применено право освобождения от налога на имущество. На основании п. 2 ст. 269 НК РФ [6] взаимозависимые иностранные кредиторы не могут полностью учитывать проценты по займам.

Налоговой орган не может проводить проверки ценообразования, в случаях, когда цена автоматически признана рыночной, даже если сделки эти формально носят статус контролируемых. В таких сделках согласно ст. 105.3 НК РФ [7]: цена определена оценщиком согласно законодательства об оценочной деятельности; цена по сделкам, заключенных в биржевых торгах, соответствует законодательству РФ или законодательству иностранного государства; цены определены в соответствии с предписанием антимонопольной службы; цена была определена в соответствии с каким-либо соглашением о ценообразовании (гл. 14.6 НК РФ).

В НК РФ перечислены два вида правонарушений, за которые предусмотрена налоговая ответственность. Согласно ст. 129.3 НК РФ [8] при неуплате или неполной уплате налога в результате применения в контролируемых сделках финансовых или коммерческих условий, которые не могут быть сопоставимы с аналогичными сделками между не взаимозависимыми лицами - налагается штраф в размере 40 \% от неоплаченных налогов, но не менее тридцати тысяч рублей. При предоставлении ложных сведений в уведомлении о контролируемых сделках и не предоставлении уведомления о контролируемых сделках налагается штраф в размере 5000 руб. (ст. 129.4 НК РФ). 
Напоследок отметим еще пару примеров последствий признания лиц взаимозависимыми: при выдаче физическому лицу займа взаимозависимой организацией у него возникает материальный доход, облагаемый НФДЛ, от экономии на процентах (ст. 212 НК РФ); при приобретении физическим лицом товаров (услуг) по заниженным ценам у взаимозависимой организации у него также возникает доход, облагаемый НДФЛ, в виде материальной выгоды.

Подведя итоги, отметим, что взаимозависимыми мо- гут быть признаны как физические, так и юридические лица. Взаимная зависимость у физических лиц (не имеющих статуса ИП) является препятствием к получению имущественного вычета. На взаимозависимых юридических лиц могут быть наложены ограничения по части определения финансовых условий заключаемых сделок (если сделка признана контролируемой). Кроме того, если ФНС посчитает, что сделки (признанные неконтролируемыми) были заключены с целью получения необоснованной налоговой выгоды, может организовать дополнительные проверки и доначислять налоги.

\section{ЛИТЕРАТУРА}

1. Налоговый кодекс Российской Федерации (часть первая)» от 31.07.1998 № 146-Ф3 (ред. от 20.07.2020) (с изм. и доп., вступ. В силу с 01.10.2020). [Электронный ресурс]. - Режим доступа: http://www.consultant.ru/document/cons_doc_LAW_19671/eab507d8eb4d9c9196ed3567f9f3ee98dd0c2f76/

2. Налоговый кодекс Российской Федерации (часть первая)» 0т 31.07.1998 № 146-Ф3 (ред. от 20.07.2020) (с изм. и доп., вступ. В силу с 01.10.2020). [Электронный ресурс]. - Режим доступа: http://www.consultant.ru/document/cons_doc_LAW_19671/ce0729faafa9043d99ffbae22f7bac69219a2a7d/

3. Налоговый кодекс Российской Федерации (часть первая)» от 31.07.1998 № 146-Ф3 (ред. от 20.07.2020) (с изм. и доп., вступ. в силу с 01.10.2020). [Электронный ресурс]. - Режим доступа: https://www.zakonrf.info/nk/105.14/

4. Письм0> ФНС России от 02.11.2012 № ЕД-4-3/18615 «0 применении отдельных положений статьи 105.3 Налогового кодекса Российской Федерации». [Электронный ресурс]. - Режим доступа: http://www.consultant.ru/document/cons_doc_LAW_137581/

5. Налоговый кодекс Российской Федерации (часть вторая) от 05.08.2000 № 117-Ф3 (ред. от 15.10.2020). [Электронный ресурс]. - Режим доступа: http:// www.consultant.ru/document/cons_doc_LAW_28165/62f621e5835790398a88f80270fe2cfob3710b3c/

6. Налоговый кодекс Российской Федерации (часть вторая) от 05.08.2000 № 117-Ф3 (ред. от 15.10.2020). [Электронный ресурс]. - Режим доступа: httр:// www.consultant.ru/document/cons_doc_LAW_28165/0cef588141a4939f2d2f5d6c0b2e1335fce57a6f/

7. Налоговый кодекс Российской Федерации (часть первая) от 31.07.1998 № 146-Ф3 (ред. от 20.07.2020) (с изм. и доп., вступ. в силу с 01.10.2020). [Электронный ресурс]. - Режим доступа: http://www.consultant.ru/document/cons_doc_LAW_19671/5e01f3a0a83a29f1741823fb9304593195004235/

8. Налоговый кодекс Российской Федерации (часть первая) от 31.07.1998 № 146-Ф3 (ред. от 20.07.2020) (с изМ. и доп., вступ. в силу с 01.10.2020). [Электронный ресурс]. - Режим доступа: http://www.consultant.ru/document/cons_doc_LAW_19671/0dcad7fcba79ce0bdb98d2f907e49de1456a8985/

( ) Терехова Валентина Владимировна (samoiova@mail.ru), Дюжов Алексей Владимирович (adujov@rambler.ru). 